\title{
LA CAZA EN UNA ECONOMÍA DE PRODUCCIÓN PREHISTÓRICA Y SUS IMPLICACIONES EN EL ARTE LEVANTINO
}

\author{
M. PÉREZ RIPOLL \\ Universidad de Alicante
}

\begin{abstract}
Se estudia el papel de la caza en el momento en que la economía de recolección deja paso a la de producción, así como la relación de esta actividad con el arte rupestre levantino y macroesquemático.
\end{abstract}

The role of hunting in the neolithic economy, and its relationship with Levantine and MacroSchematic Rock Art are studied.

La caza en una economía de producción prehistórica suele relegarse y a veces minimizarse debido a que se resalta la importancia de la ganadería y agricultura como fenómeno nuevo, omitiendo toda referencia a la economía anterior. Sin embargo, pensamos que no es así. A pesar de estas innovaciones, la caza sigue teniendo una consideración cuya relevancia depende del momento cultural y de cada yacimiento en concreto. A este respecto se hace necesario precisar el momento y los yacimientos que denotan la transformación de una economía en otra, así como el significado de ésta.

El momento se sitúa en el tránsito del Epipaleolítico al Neolítico. Desde el punto de vista zoorqueologico, estamos en condiciones de poder precisar este tránsito gracias a las aportaciones de varios yacimientos que contienen un nivel epipaleolítico con geométricos y superpuesto a éste otro neolítico con cerámicas impresas. Así, podemos citar los yacimientos de La Cocina (Valencia), Botiquería dels Moros (Teruel), La Roca (Alicante) y Valdecuevas (Jaén).

La economía de La Cocina es plenamente cazadora en los niveles epipaleolíticos (1), y a pesar de

(1) Un resumen puede verse en J. Fortea y otros, 1987. El estudio exhaustivo está en preparación. la cerámica impresa del nivel III que lo sitúa en un momento neolítico, esta actividad sigue practicándose de una forma exclusiva; sólo al final aparecen los primeros animales domésticos. Además, el estudio cultural se correlaciona con el zoorqueológico (FORTEA y OTROS, 1987), y la visión conjunta muestra con claridad que el epipaleolítico geométrico se neolitiza a partir de estímulos que son externos a este yacimiento.

En La Roca se plantea el tránsito de un modo muy parecido. El nivel epipaleolítico con geométricos tiene superpuesto otro nivel superficial que contiene algunos fragmentos de cerámica cardial (CA$\mathrm{CHO}, 1986$ ). A primera vista, puede pensarse que este nivel presenta intrusiones por el hecho de ser superficial, sin embargo los restos de fauna estudiados no detectan ningún elemento que pueda provenir de otro momento cultural, y dan por bueno este nivel. Pues bien, la misma composición de fauna se da tanto en el nivel epipaleolítico como en el superficial, y por consiguiente la actividad cazadora (basada principalmente en el ciervo y en la cabra hispánica) que define a la economía de los niveles epipaleolíticos se sigue continuando en el nivel superficial, con lo que se pone de manifiesto la aloctonía de los fragmentos de cerámica y se incide en un proceso de neolitización semejante al expuesto en La Cocina. 
Botiquería (ALTUNA, 1978) presenta un panorama idéntico. El Epipaleolítico geométrico (niveles 2 a 5 ) se caracteriza por el desarrollo de la caza del ciervo y conejo, y en menor importancia la del caballo, rebeco y jabalí. El neolítico (niveles 6 a 8) también presenta una economía cazadora, que siguiendo la tradición del nivel anterior básicamente se compone de ciervos y conejos.

Valdecuevas (I. SARRION, 1980) muestra una superposición cultural semejante a la descrita: un nivel epipaleolítico con geométricos (capas 8 a 12), en $\in$ l que la caza de la cabra hispánica y el ciervo constituyen la actividad principal (el rebeco y aún más el jabalí son esporádicos), y otro neolítico (capas 7 a 4), que a diferencia de los otros tres yacimientos contiene varios restos de oveja y el total de huesos domésticos es superior al de salvajes. Este hecho puede explicarse si se considera este nivel más reciente que el correspondiente al neolítico de los otros yacimientos.

Si por el contrario examinamos yacimientos plenamente neolíticos, como Cova de l'Or y La Sarsa, nos encontramos con un desarrollo cultural y una economía agrícola y ganadera, cuyos influjos nada tienen que ver con el Epipaleolítico, y que forzosamente deben de buscarse en el Mediterráneo Oriental (MARTI y OTROS, 1987; PÉREZ, 1980). La caza no desaparace, y alcanza una cierta relevancia, pues alrededor de un $25 \%$ del NR de Cova de l'Or (M. PÉREZ, 1980) y de un 30\% de La Sarsa (BOESSNECK, 1980) pertenece a especies salvajes, de las que el ciervo, descontando el conejo, adquiere el valor más elevado $(5,9 \%$ sobre el NR en Cova de l'Or y un 4\% en la Sarsa); la cabra hispánica tan sólo alcanza un $1,5 \%$ en Or y un $1,2 \%$ en Sarsa.

Sin embargo, en el yacimiento eneolítico de la Ereta del Pedregal el NR de especies domésticas alcanza el $45 \%$ sobre el total de restos, y el ciervo se convierte en la segunda especie más importante con un $28,7 \%$, muy cerca del $30 \%$ de los ovicaprinos. El porcentaje de la cabra hispánica es mucho menor, un $3,8 \%$ y del conejo de un $10,8 \%$. Con estos resultados es evidente que la caza aún constituye una actividad importante en la economía de este poblado. (PÉREZ, en prensa).

Fuera de la área valenciana estas cifras descienden en Zambujal (Portugal) (DRIESCH y BOESSNECK, 1976) el NR de especies salvajes para niveles calcolíticos se sitúa entre el 11 y el $15 \%$, que se asemeja al de los yacimientos de la Edad del Bronce; el ciervo tan sólo alcanza un $3 \%$ y el conejo en- tre un 6 y un $10 \%$. En los niveles calcolíticos de Cerro de la Virgen (DRIESCH, 1972) estos porcentajes son algo más elevados: entre un 16 y $21 \%$ de NR de especies salvajes, de las que el ciervo ocupa una cifra baja $(0,8-2 \%)$ y el conejo llega a ser predominante (13 al $17 \%$ ).

La caza experimenta un descenso notable en el yacimiento de la Edad del Bronce del Cabezo Redondo (DRIESCH y BOESSNECK, 1969), ya que las especies salvajes sólo comprenden el $13 \%$ del $\mathrm{NR}$, de las que un $10 \%$ son de conejo y tan sólo un $0,6 \%$ y un $0,1 \%$ de ciervo y cabra hispánica respectivamente. En el nivel argárico del Cerro de la Virgen (DRIESCH, 1972), las especies salvajes se sitúan en el $11 \%$ del NR, siendo un $8 \%$ para el conejo y un 2,5\% para el ciervo. En Cerro de La Encina (DIETER, 1976), el porcentaje de las especies. salvajes es del $11,5 \%$, del que un $7 \%$ es para el conejo, un $1,4 \%$ para el ciervo y un $0,3 \%$ para la cabra hispánica. En la Cuesta del Negro (DIETER, 1976) son aún más bajos, un $5,4 \%$ de especies salvajes, de las que un $3,2 \%$ pertenece al conejo, $1,4 \%$ al ciervo y los restos de cabra hispánica son esporádicos.

A lo largo de esta breve exposición se puede observar cómo la importancia de la caza cambia según la época y las circunstancias particulaes de cada yacimiento. En un principio coexiste una economía plenamente cazadora (Neolítico de tradición epipaleolítica) con otra agrícola y ganadera (Neolítico pleno) en la que el papel de la caza no es despreciable. Durante el Eneolítico, en unos yacimientos (Ereta del Pedregal) la caza sigue siendo importante y en otros menos. Pero con la Edad del Bronce se convierte en una actividad marginal, que perdura en las etapas posteriores e incluso en medievales (BENITO, 1985).

Sin embargo, es preciso delimitar el significado que tiene la caza en una economía recolectora y cazadora de otra agrícola y ganadera. Esta tarea se puede abordar bajo dos métodos: el estudio de la selección de los animales a través de sus edades de muerte, y el estudio del comportamiento paleoetnológico del proceso de la carnicería. Respecto al primero, está en proceso de elaboración, y en breve se publicará de forma extensa. El segundo se puede abordar con toda amplitud (PÉREZ, Tesis Doctoral inédita).

El modelo paleoetnológico que se ha podido obtener a través del estudio de varios yacimientos difiere radicalmente según el tipo de economía. Dicha diferencia puede establecerse tanto en las mar- 
cas o cortes de carnicería como en las fracturas de los huesos. En una economía cazadora, los animales después de haber sido pelados se someten a un cuidadoso descarnado y sus huesos son posteriormente desarticulados para proceder a su fracturación, previa limpieza de los mismos. Este proceso origina una serie de marcas, cuyo estudio morfológico puede ser de gran utilidad para tipificar los modelos paleoetnológicos, y con ello el tipo de explotación económica. Las incisiones, los rascados y las diversas estriaciones corresponden a esta clase de marcas. Por el contrario, en una economía agrícola y ganadera éstas se circunscriben únicamente a las incisiones, que, a su vez, presentan rasgos diferenciadores.

Esta diversidad surge por el destino final de los huesos, además de las distintas modalidades en la preparación de la carne. En una sociedad cazadora, los huesos son sistemáticamente fracturados, tanto los grandes como los pequeños incluso los de tejido esponjoso, para obtener la médula. La importancia que esta sustancia tendría en la alimentación cabe establecerla por la valoración del esfuerzo que supone la extracción del periostio, a veces muy complicada como en el caso de la tibia, o el trabajo del pelado de las patas para fracturar las falanges de reducida capacidad medular. Por el contrario, en una sociedad agrícola y ganadera, el periostio, la grasa y la médula de los huesos se destinan mayoritariamente a la alimentación de los perros, como hemos podido comprobar en Cova de l'Or y la Ereta del Pedregal. Por esta razón, en esta sociedad faltan las marcas que corresponden a la preparación del hueso para ser fracturado, que básicamente son rascados longitudinales y alargados. Al mismo tiempo, las fracturas por mordedura nada tienen que ver ni en su morfología ni en su situación con las de percusión intencionada, y, por consiguiente, el estudio detallado de las mismas proporciona una base sólida para poder dilucidar el carácter económico de un yacimiento.

En La Cocina y debido a las concreciones calcáreas no ha sido posible estudiar las marcas, pero sí las fracturas. La intencionalidad de las mismas es evidente tanto en el Epipaleolítico como en el Neolítico; sólo al final de este último nivel aparecen los primeros huesos mordidos por perros. Estos aspectos encajan perfectamente con el carácter cazador de la economía de este yacimiento. En La Roca la variedad morfológica de las marcas se encuentrá bien representada, especialmente en el ni- vel epipaleolítico del corte interior, pues el exterior (que es precisamente el que contiene el nivel con cerámicas) se halla muy alterado por elementos biológicos, especialmente por las raíces de las plantas. Las fracturas intencionadas se encuentran tanto en el nivel epipaleolítico como en el superficial, sin que exista elemento alguno que indique un cambio.

Por el contrario, tanto en Cova de l'Or como en la Ereta las marcas morfológicas que existen son únicamente incisiones que se relacionan con la desarticulación. Huellas de descarnado son escasas y rascados tan sólo ha aparecido un caso. Este panorama queda plenamente confirmado por las fracturas. La mayoría fueron originadas por perros, y las intencionales son muy pocas. Es evidente, por tanto, la constatación de la transformación surgida en el tratamiento paleoetnológico.

Hemos de concluir, que la neolitización que se produce a partir del epipaleolítico con geométricos nada tiene que ver con su dinámica interna, como así lo demuestra el estudio zooarqueológico, pues ni la economía cazadora sufre cambio alguno ni el tratamiento paleoetnológico carnicero experimenta algún tipo de modificación con la llegada de la cerámica. La neolitización únicamente se puede seguir por las innovaciones culturales, que se circunscriben básicamente a la cerámica. Este modelo de neolitización es el opuesto al que se da en el Próximo Oriente, ya que allí se asiste a la evolución de la fauna doméstica a partir de ciertas especies salvajes antes de la aparición de la cerámica. Una vez producido el cambio económico, las características del proceso carnicero son muy semejante entre Cova de l'Or, la Ereta y los yacimientos de la Edad del Bronce que estamos estudiando.

Entre otras consideraciones, la delimitación del sentido exacto que tiene la práctica de la caza adquiere una gran importancia en el momento de abordar las representaciones artísticas. Lo que más interesa es relacionar las aportaciones zooarqueológicas con el arte rupestre, y en concreto con el levantino, ya que el arte macroesquemático por sus originales aportaciones, tamaño de sus figuras y estilo no guarda relación con aquél (HERNANDEZ, 1985).

Si el arte levantino se sitúa a finales del V milenio a. C., como así parecen indicar las superposiciones de ciertas pinturas y la cronología que proporciona la cerámica de Cova de l'Or con decoraciones de este estilo, asistimos a un elemento más de la neolitizacion (FORTEA y AURA, 1987). 
Las escenas de caza, o de animales salvajes, tales como ciervos o cabras hispánicas, se explican por los porcentajes no despreciables que estos animales aún conservan en el neolítico de Cova de l'Or y La Sarsa. Ahora bien, estas escenas han perdido el sentido estricto que la caza o los animales tendrían en una sociedad recolectora y cazadora; el estudio paleoetnológico así lo indica, ya que en estos yacimientos se evidencia una transformación, y no una imbricación de elementos nuevos con otros de tradición epipaleolítica, como ya hemos observado, que vendría a denotar, coincidiendo con las opiniones de FORTEA y AURA (1987), el sentido de prestigio social que adquiría la caza, practicada de un modo amplio atendiendo al buen número de arqueros que aparecen en las paredes de los abrigos y a la relativa importancia del número de huesos pertenecientes al ciervo y a la cabra hispánica hallados en estos yacimientos. En esta misma dirección apunta la explotación ganadera de este momento; la caza no constituye una necesidad básica como fuente aportadora de alimentos, para eso está la ganadería (adẹmás de la agricultura); de esta última no se obtiene el máximo rendimiento en carne pues los animales son sacrificados jóvenes o muy jóvenes en un elevado porcentaje, debido a que la presión social no es superior a las necesidades alimenticias (PÉREZ, 1980).

Todo lo contrario habría que pensar si las gentes del epipaleolítico neolitizado (ejemplo Cocina III) fuesen las autoras del Arte Levantino, porque ellas están aún inmersas en una economía cazadora y las escenas pintadas cobrarían un sentido diferente al que corresponde si mantenemos que el centro neolitizador proviene de yacimientos como Cova de l'Or y la Sarsa. No es lo mismo recibir una cerámica ya fabricada que crear una concepción artística que forma parte de una cultura en la que también se encuentra implicado el proceso paleoetnológico que en nada ha evolucionado.

Por esa razón, del mismo modo que en las capas superiores del nivel III de Cocina asistimos a la introducción de animales domésticos y a la aparición de las primeras fracturas originadas por mordeduras de perro, podemos situar la extensión del Arte Levantino a estas tierras del interior. No puede excluirse que acompañara a la cerámica, pero las implicaciones económicas y paleoetnológicas serían difíciles de argumentar.

La perduración del Arte Levantino a través del Eneolítico tiene su soporte en la abundancia de la caza, especialmente del ciervo, en el yacimiento de la Ereta del Pedregal. Ahora bien, conservando el sentido que anteriormente se ha indicado.

Durante la Edad del Bronce, las cosas parecen haber cambiado. La caza es mínima, tal vez porque los espacios de bosque se hayan reducido con la expansión de la agricultura y ganadería, o tal vez porque la caza se haya convertido en una práctica minoritaria reservada a grupos sociales poderosos, que puede estar en consonancia con la utilización del caballo como animal de monta, que denotaría rango y prestigio social.

En definitiva, y coincidiendo con las aseveraciones de F. Fortea y E. Aura (1987), el Arte Levantino debe de contextualizarse con el registro arqueológico a fin de sustraerlo de la parte meramente formal, lo que indudablemente conlleva riesgos, pero es imprescindible para darle un sentido histórico.

\section{BIBLIOGRAFÍA}

ALTUNA, J. 1978: «Fauna del yacimiento prehistórico de Botiquería dels Moros, Mazaleón (Teruel)»y. Cuadernos de Prehistoria y Arqueología Castellonenses, 5, p. 139-142.

BENITO, M. 1985: «Aproximación al estudio de la Fauna del Castillo de la Mola (Novelda, Alicante). Una aportación al estudio de la economía medieval\%. En Excavaciones medievales en el Castillo de la Mola (Novelda-Alicante). Novelda, p. 101-117.

BOESSNECK, J. y A. von d. DRIESCH 1980: «Tierknochenfunde aus vier südspanischen höhlen». En Studien über Frhühe Tierknochenfunde von der Iberischen Halbinsel, 7. München.

CACHO, C. 1986: «Nuevos datos sobre la transición del magdaleniense al epipaleolítico en el País Valenciano: el Tossal de la Roca». Boletín del Museo Arqueológico Nacional, IV, p. 117-129.

DIETER, H. 1976: «Tiernuchenfunde aus bronzereihichen Siedlungen bei Monachil und Purullena (Provinz Granada)». Studien über Frühe TierknochenFunde von der Iberischen Halbinsel, 6, München.

DRIESCH, A. v. d. 1972: «Ostcoarchäologische Untersuchungen auf der Iberischen Halbinsel». Studien über Frühe Tierknochenfunde von der Iberischen Halbinsel, 3, München.

DRIESCH, A. v. d. y BOESSNECK, J. 1969: «Die Fauna des Cabezo Redondo bei Villena (Prov. Alicante). Studien über Frühe Tierknuchenfunde von der Iberischen Halbinsel, 1, München.

- 1976: «Die Fauna vom Castro de Zambujal. (Fundmaterial der Grabugen von 1966 bis 1973 mit Ausnahme der Zwingerfunde)». Studien über Frühe Tierknochenfunde von der Iberischen Halbinsel, 5.

FORTEA, I.; MARTI, B.; FUMANAL, P. y OTROS 1987: «Epipaleolítico y neolitización en la zona oriental de la Península Ibérica». Premières Communautés Paysannes en Méditerranée occidentale, Montpellier, 1983, p. 581-591. 
FORTEA, J. y AURA, E. 1987: «Una escena de vareo en La Sarga (Alcoy). Aportaciones a los problemas del arte levantino». A.P.L. XVII, T. I, p. 97-122.

HERNÁNDEZ, M. 1985: «Arte rupestre». Arqueología en Alicante. 1976-1986. P. 157-161.

MARTÍ, B.; FORTEA, J.; BERNABEU, I. y OTROS 1987: «El neolítico antiguo en la zona oriental de la Península Ibéri- ca». Premières Communautés Paysannes en Méditerranée occidentalle, Montpellier, 1983, p. 607-619.

PÉREZ, M. 1980: «La fauna de vertebrados (Cova de l'Or)». En «Cova de l'Or (Beniarrés-Alicante)». S.I.P., Serie de Trabajos Varios, n. ${ }^{\circ} 65$, V. II.

- 1987: Tesis Doctoral, inédita.

SARRIÓN, I. 1980: «Val de Cuevas. Estación Meso-Neolítica en la Sierra de Cazorla (Jaén)». Saguntum, 15, p. 23-56. 